\title{
The influence of fetal sex on patterns of change in anti-Mullerian hormone during pregnancy
}

\author{
Ryan Empey, MD, ${ }^{1}$ Donna Santillan, $\mathrm{PhD},{ }^{1}$ Mark Santillan, MD, ${ }^{1}$ Eric Tyler, $\mathrm{BS}^{2}$ \\ Stephen Hunter, MD, PhD, ${ }^{1}$ Elaine Smith, MPH, PhD, ${ }^{3}$ Barbara Stegmann MD, MPH, ${ }^{1}$
}

Keywords: anti-Mullerian hormone, fetal sex, pregnancy

\section{Introduction}

Maternal anti-mullerian hormone declines sharply between 13-15 weeks, likely as a result of feto-placental signaling. Fetal $\mathrm{AMH}$ levels are known to be widely disparate after the first trimester, with high levels in male and absent levels in female. However, it is unclear as to whether differing fetal $\mathrm{AMH}$ levels influence the pattern of change of maternal AMH. Our objective was to examine $\mathrm{AMH}$ throughout gestation to determine if the maternal concentration varies according to the gender of the fetus.

${ }^{1}$ Department of Obstetrics and Gynecology, Carver College of Medicine, University of lowa Hospitals and Clinics, lowa City, IA, 52242

${ }^{2}$ Carver College of Medicine, University of lowa Hospitals and Clinics, Iowa City, IA, 52242

${ }^{3}$ Department of Epidemiology, College of Public Health, University of lowa, lowa City, IA, 52242

\section{Methods}

De-identified maternal plasma samples along with demographic and pregnancy outcome data were obtained from the IRB-approved Maternal-Fetal Tissue Bank at the University of lowa. All women were $\geq 18$ years old and had an uncomplicated singleton delivery at $\geq 37$ weeks. AMH was tested using the Genll AMH ELISA assay (Beckman Coulter). Bicinchoninic acid (BCA) assay (Pierce) was used to measure total protein. $\mathrm{AMH}$ was normalized to total protein prior to analysis. Mean $\mathrm{AMH}$ and $\mathrm{AMH}$ by gestational age between women carrying boys vs. girls was compared with logistic regression modeling.

\section{Results}

154 samples from 107 women (51 males and 56 females) were analyzed. Because of multiple sampling, 78 samples were from boys and 76 samples were from girls. No differences in maternal age, gestational age at delivery, or number of samples from

Please cite this paper as: Empey R, Santillan D, Santillan M, Tyler E, Hunter, S, Smith, E, Stegmann B. The influence of fetal sex on patterns of change in anti-Mullerian hormone during pregnancy. Proc Obstet Gynecol. 2012 ;2(3):Article 4 [ 2 p.]. Available from: http://ir.uiowa.edu/pog/. Free full text article.

Corresponding author: Donna Santillan, Department of Obstetrics and Gynecology, University of lowa, 463 MRF, 200 Hawkins Drive, lowa City, IA 42242. donna-santillan@uiowa.edu. 
each gestational category between sexes. Mean AMH levels were not different if carrying a male vs. female fetus $(p=0.12)$. However, when stratified by gestational age, mean AMH ( \pm SEM) at $11-15$ weeks was significantly higher in women with male fetuses $(2.0 \pm 0.30 \mathrm{ng} / \mathrm{mL})$ vs. female fetuses $(0.94 \pm 0.20 \mathrm{ng} / \mathrm{mL})(\mathrm{p}=0.008)$.

\section{Conclusion}

AMH falls in pregnancy between 11-15 weeks regardless of fetal sex; however, maternal $\mathrm{AMH}$ is significantly higher in pregnancies carrying male compared to female fetuses. This may represent a sexually dimorphic response in the ovary to feto-placental signaling. 